\title{
Anatomical and morphometric analysis of a new species of Leitoscoloplos (Annelida: Orbiniidae) with numerous stomach papillae, from the Gulf of California, Eastern Pacific
}

\author{
Pablo Hernández-Alcántara1 ${ }^{1}$ Vivianne Solís-Weiss ${ }^{2,3}$ \\ ${ }^{1}$ Unidad Académica de Ecología y Biodiversidad Acuática, Instituto de Ciencias del Mar y Limnología, Universidad \\ Nacional Autónoma de México, Circuito exterior s/n, Cdad Universitaria, D.F., 04510, Mexico \\ ${ }^{2}$ Unidad Académica de Sistemas Arrecifales, Instituto de Ciencias del Mar y Limnología, Universidad Nacional \\ Autónoma de México, Prol Av Niños Heroes s/n, Puerto Morelos Quintana Roo, 77580, Mexico \\ ${ }^{3}$ E-mail:solisw@cmarl.unam.mx
}

Key words: Leitoscoloplos emendation, Leitoscoloplos multipapillatus sp. nov., Mexican Pacific, Polychaeta

\begin{abstract}
The morphological and morphometric analyses of 88 orbiniids from the continental shelf of the Gulf of California lacking thoracic neuropodial hooks confirmed that a new species, Leitoscoloplos multipapillatus, described herein, is present along with Leitoscoloplos panamensis (Monro. 1933), already recorded there. The new species is closely related to L. panamensis, but can be clearly separated from this, and all other species of Leitoscoloplos, by the unique presence of up to 14 stomach papillae per chaetiger. A third taxon was identified, Leitoscoloplos sp., which is morphologically indistinguishable from L. panamensis, except for the presence of 1-2 stomach papillae on 1-2 segments, a feature that although important was not considered significant enough to erect a new species. Morphometric analyses between the closely related species, L. panamensis (including its type material) and L. multipapillatus sp. nov., in addition to Leitoscoloplos sp., were used to verify the new species. The generic diagnosis is emended to include species with numerous stomach papillae. Anatomical examination of these species was carried out with SEM to illustrate their characteristic features and corroborate the presence of capillary chaetae only along the thorax of the analysed specimens, as well as the unusual occurrence of stomach papillae.
\end{abstract}

\section{Contents}

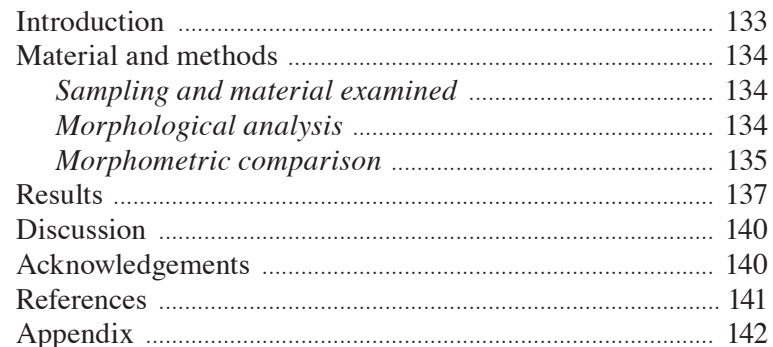

\section{Introduction}

The family Orbiniidae Hartman, 1942 comprises a group of deposit-feeding polychaetes, distributed in all the world seas. Following Hartman's (1957) comprehensive systematic review of the orbiniids, which included redefining all recognized genera, the family was divided into the sub-families Orbiniinae (with one peristomial ring) and Protoariciinae (with two rings). Subsequently, Blake's studies (1996) on their larval and juvenile morphology, established that some species included in the sub-family Protoariciinae were juveniles of larger species of Orbiniinae, and that the first achaetous ring in orbiniids was peristomial, while the second ring is now thought to be an achaetous segment (Fauchald and Rouse, 1997). In 2000 Blake reclassified the Orbiniidae into three sub-families: Methanoariciinae, Microorbiniinae, and a new 'combined' Orbiniinae, which included many genera of the former Protoariciinae. However, the phylogenetic relationships of orbiniid taxa reconstructed by Bleidorn (2005), based on the sequence data of the mitochondrial $16 \mathrm{~S}$ rRNA and nuclear 18S rRNA genes, showed no support for the hypothesis that the Protoariciinae are juveniles of Orbiniinae. Therefore, the support for maintaining these clades became very weak and the monophyly of some of the genera is in doubt (Bleidorn, 2005; Bleidorn et al., 2009). Presently, approximately 150 species and 24 genera are recognized (Read and Fauchald, 2012).

The genera Leitoscoloplos, Naineris, Orbinia, Phylo and Scoloplos are the most speciose taxa in the Orbiniidae. In particular, Leitoscoloplos Day, 1977 includes those orbiniids that truly lack thoracic neuropodial 
hooks (Day, 1977); the genus was thoroughly reviewed by Mackie (1987), who suggested a possible polyphyletic origin of the species currently within that taxon.

Originally, the genus was erected by Monro (1933) as Haploscoloplos to accommodate those species which were generally similar to Scoloplos but lacked hooks. Subsequently, Monro's short definition was complemented by Hartman (1957) and Day (1973), but the absence of thoracic neuropodial hooks remained the defining character of the genus. Unfortunately, the type species originally selected by Monro, Scoloplos cylindrifer Ehlers, 1904 from New Zealand, was later found to possess an anterior row of short slender hooks that is easily overlooked, and Haploscoloplos became a synonym of Scoloplos (Day, 1977). However, Day (1977) could observe that several species did fit Monro's generic definition of Haploscoloplos and proposed to name the new genus Leitoscoloplos to include the orbiniids with no hooks and with only crenulated capillaries in the thorax. Later, following Mackie's (1987) excellent re-examination of the species assigned to this genus, five new taxa were described. Nowadays, 24 species (including the new species described in this study) are recognized in the genus Leitoscoloplos.

Orbiniids are polychaetes common in sandy and muddy bottoms throughout the world, with most species distributed at relatively shallow depths (Rouse, 2001; Eibye-Jacobsen, 2002). In the Tropical Eastern Pacific, seven species have been recorded of the 24 described to date. In the course of the revision of the polychaetes collected for this study, several specimens from the family Orbiniidae were separated from their congeners: their pointed prostomium and the presence of only capillary chaetae in the thoracic neuropodia clearly indicated that they belonged to the genus Leitoscoloplos. Hernández-Alcántara and Solís-Weiss (1999), following Mackie (1987), initially identified these as L.panamensis (Monro, 1933). However, as a result of more in-depth observations of those specimens, unusual morphological features were detected in some individuals, i.e., numerous stomach papillae on the ventral surface of the body, besides the characteristic podal and subpodal papillae, that made us re-examine their taxonomic status. The comparison of these unusual orbiniids with the type material of L. panamensis corroborated that the former were different.

Stomach papillae are not unknown in the genus Leitoscoloplos, since in L. ovobatus Mackie, 1987, from New England, USA, a single small stomach papilla is present on 2-3 chaetigers at the thorax-abdomen junction. The occurrence and distribution of these stomach papillae are considered rather important to help separate species in other orbiniid genera, particularly in Orbinia and Phylo.

Based on the above, we herein describe Leitoscoloplos multipapillatus sp. nov., collected on the continental shelf of the Gulf of California, mainly characterized by its numerous stomach papillae, and compare it to the closely related species L. panamensis and Leitoscoloplos sp. The status of the latter is discussed. Our taxonomic observations and morphometric analyses necessitated emendation of the generic diagnosis to include species with abundant stomach papillae. SEM images were used to confirm the presence of only capillary chaetae in the neuropodia and the occurrence of these unusual papillae on the specimens from the Gulf of California.

\section{Material and methods}

\section{Sampling and material examined}

Sampling was carried out on soft bottoms in the Gulf of California, Eastern Pacific (23-31 $\left.38^{\circ} \mathrm{N}, 105-107^{\circ} \mathrm{W}\right)$, between 9 and $104 \mathrm{~m}$ depth on board the O/V 'El Puma' ('Cortés' expeditions) and in Mazatlán Bay. The sediment was collected with a Smith-McIntyre $\left(0.1 \mathrm{~m}^{2}\right)$ or Van Veen $\left(0.06 \mathrm{~m}^{2}\right)$ grab, and sieved through a $0.5 \mathrm{~mm}$ mesh. The biological material was fixed in $10 \%$ formalin and preserved in $70 \%$ ethanol.

The specimens were examined under dissection and compound light microscopes, both with camera lucida for drawings. For SEM studies, specimens were dehydrated via a graded ethanol series, liquid- $\mathrm{CO}_{2}$ dried at critical point, coated with gold and examined in a JEOL JSM6360LV microscope at the Instituto de Ciencias del Mar y Limnología (ICML), Universidad Nacional Autónoma de México (UNAM). The identified specimens and type material of the new species were deposited in the Colección Nacional de Poliquetos of the ICML, UNAM (CNP-ICML-UNAM; DFE. IN.061.0598), and at the British Natural History Museum (BMNH). The type series of Leitoscoloplos panamensis in the British Natural History Museum was also examined.

\section{Morphological analysis}

Some morphological characters have been used under different names in the family Orbiniidae after Hartman's (1957) study; that is why the modifications 
proposed by Mackie (1987), as well as those introduced by Blake (1996) and Eibye-Jacobsen (2002), were used here to standardize the description of the species. The abdomen is considered to start where the neuropodia become cylindrical; besides, the abdominal neuropodia bear a few capillaries, while the thoracic neuropodia have fan-shaped bundles of numerous chaetae. A single postchaetal lobe is present in the notopodia, and the chaetiger at which this lobe appears can be a diagnostic character for some species. Contrary to the notopodia, an important number of morphological structures are helpful in the neuropodia for the identification of the different taxa. The number and distribution of papillae associated with the parapodia are important to identify several genera of Orbiniidae. In the course of this study, podal, subpodal and/or stomach papillae were observed in the neuropodia of specimens of Leitoscoloplos, and their distribution on the thorax and/or abdomen were considered significant to separate the taxa. In particular, the podal papillae are postchaetal processes, which are part of the subdivided neuropodial lobes proper; the term subpodal papilla refers to papillae immediately below the neuropodia, present in a transverse row, ventral and somewhat posterior to the neuropodia, while stomach papillae are papillae clearly placed close to the ventral midline of the body (Mackie, 1987; EibyeJacobsen, 2002). These stomach papillae have also been described by some authors as subpodal papillae extended almost to the ventral midline of the body (EibyeJacobsen, 2002).

Morphological differences among Leitoscoloplos panamensis, L. multipapillatus sp. nov. and Leitoscoloplos sp. are difficult to recognize, except for the number of stomach papillae. Usually, the subpodal and stomach papillae are separated by a gap, and the stomach papillae are counted from this gap to the ventral midline of the body, but in the new species described in this study, the distribution of the subpodal and stomach papillae is occasionally continuous (see discussion). This is why they look like additional papillae on the ventral surface, making it difficult to distinguish between them, as indicated by Mackie (1987) and EibyeJacobsen (2002).

The emendations of Eibye-Jacobsen (2002) to the genus Leitoscoloplos allow the inclusion of species with up to seven subpodal papillae; in the new species herein described, all the diagnostic characters corresponded to Leitoscoloplos, except for their numerous (up to 14) stomach papillae, which is why it was necessary to extend the diagnosis of the genus to include species with numerous stomach papillae.

\section{Morphometric comparison}

To compare the specimens identified as Leitoscoloplos panamensis, L. multipapillatus sp. nov. or Leitoscoloplos sp., 14 morphological features commonly used in orbiniid taxonomy were measured: body length to chaetiger $50(\mathrm{Bln})$; thoracic width at chaetiger $10(\mathrm{Tw})$, without parapodia; number of thoracic chaetigers (Tc); thoracic length (Tln); first chaetiger with branchiae (fBr); first neuropodium with bifurcate lobes (fBL); first chaetiger with interramal cirri (fIC); number of chaetigers with interramal cirri (cIC); first chaetiger with subpodal papillae (fSpP); number of chaetigers with subpodal papillae (cSpP); maximum number of subpodal papillae (mSpP); first chaetiger with stomach papillae (fStP); number of chaetigers with stomach papillae (cStP); maximum number of stomach papillae (mStP).

Orbiniids are very long, usually over 200 segments as adults (Eibye-Jacobsen, 2002) but, as all specimens in this study lacked their posterior regions, length measurements were standardized to 50 chaetigers. The measurements were made with an eyepiece micrometre in 38 specimens of L. panamensis collected in the Gulf of California, three syntypes of L. panamensis, 38 specimens of L. multipapillatus sp. nov., and 12 specimens of Leitoscoloplos sp. The 14 characters chosen were submitted to an exploratory analysis to identify general patterns such as their variability, which was performed with box diagrams and the Kruskal-Wallis test $(\mathrm{KW})$ to identify differences between taxa; $p$ values of less than 0.05 were considered statistically significant (Zar, 1996).

Based on the above mentioned morphometric measurements, a Principal Component Analysis (PCA) was carried out to evaluate the relationships between the three taxa under study, and to identify which variables best explained their variability (Hair et al., 1999). Later, a Discriminant Analysis using the forward stepwise method was applied to determine the best combination of variables that would discriminate between the taxa collected and the type material of $L$. panamensis. The standard statistic Wilks' lambda (ranking from 1: no discriminatory power, to 0 : perfect discriminatory power) was used to detect the statistical significance of the discriminatory power of the current model, where the groups must be differentiated at a significant level of $p<0.0001$ to be considered true species. The characters' selection for the model were made by the F-remove statistic, which selected the variables with Fvalues greater than 1 . The partial Wilks' lambda index was employed to evaluate the contribution of each 

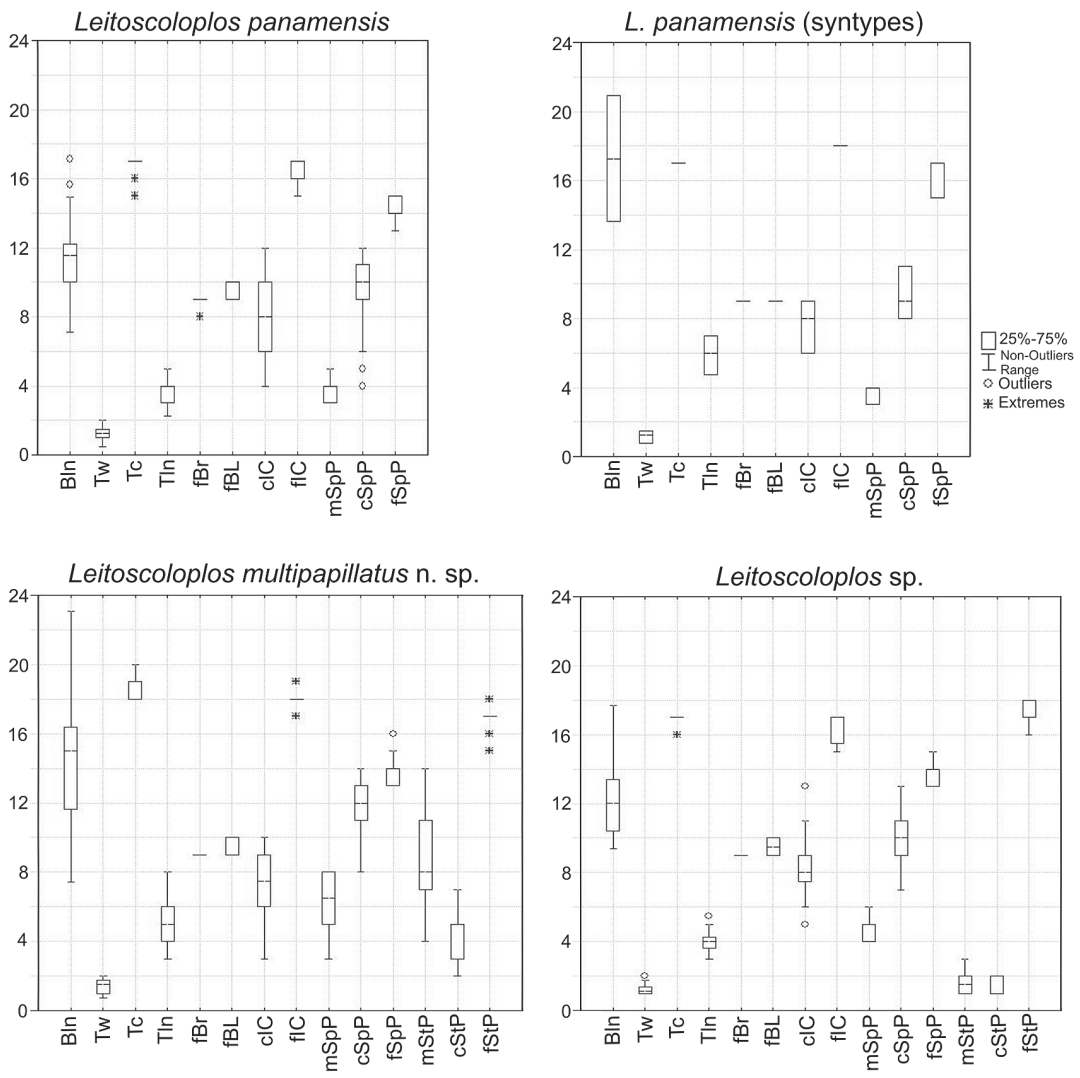

Fig. 1. Variation in 14 morphological characters in three Leitoscoloplos taxa. Character abbreviations are defined in the materials and methods section.
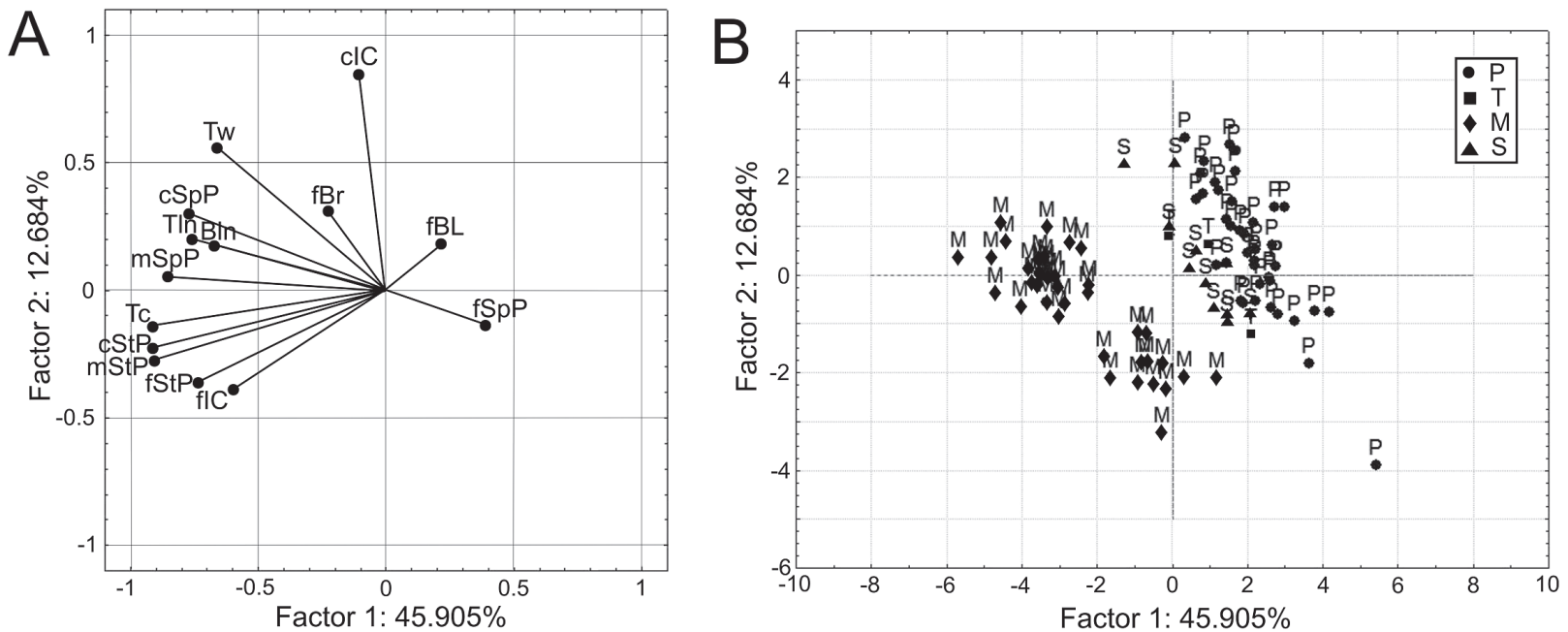

Fig. 2. PCA diagrams for the first two factors. A) Biplot of the 14 morphological characters; B) distribution of all specimens of Leitoscoloplos panamensis (P), syntypes of L. panamensis (T), Leitoscoloplos multipapillatus sp. nov. (M) and Leistoscoloplos sp. (S). Morphological abbreviations are explained in the materials and methods section. 
character to the discrimination between groups, where 0 means a perfect discriminatory power. Next, a canonical analysis was carried out to compute the discriminant functions and to show how the morphological variables discriminate the specimens/species (Hair et al., 1999). All morphometric analyses were carried out using the software Statistica 7.0 for Windows.

\section{Results}

The anatomical and morphometric comparison among the taxa under study yielded the following results:

Only three characters were significantly similar for all analysed taxa (Fig. 1): 1) except for one specimen from L. panamensis (chaetiger 8), in all taxa the branchiae (fBr) started on chaetiger $9(\mathrm{KW}=1.395$, $p=0.7068) ; 2$ ) although their variability was very high, the average number of chaetigers bearing interramal cirri (cIC) was similar in the three taxa (KW=2.736, $p=0.4341) ; 3$ ) the specimens belonging to L. panamensis were slightly shorter (Bln) than the other taxa, but this difference was not significant $(\mathrm{KW}=7.346$, $p=0.0617$ ).

Of course, the measurements linked to stomach

Table 1. Eigenvalues for the first four principal components.

\begin{tabular}{lllll}
\hline $\begin{array}{l}\text { Factor } \\
\end{array}$ & $\begin{array}{l}\text { Eigen- } \\
\text { value }\end{array}$ & $\begin{array}{l}\text { \% Total } \\
\text { variance }\end{array}$ & $\begin{array}{l}\text { Cumulative } \\
\text { eigenvalue }\end{array}$ & $\begin{array}{l}\text { \% Cumulative } \\
\text { variance }\end{array}$ \\
\hline 1 & 6.43 & 45.9 & 6.4 & 45.9 \\
2 & 1.78 & 12.7 & 8.2 & 58.6 \\
3 & 1.25 & 8.9 & 9.5 & 67.5 \\
4 & 1.07 & 7.6 & 10.5 & 75.1 \\
\hline
\end{tabular}

papillae showed that L. multipapillatus sp. nov. has the highest number of stomach papillae (mStP) and of chaetigers with such papillae (cStP) compared to Leitoscoloplos sp., but in both taxa these papillae start on similar chaetigers (16 to 18) (Fig. 1). On the other hand, the number of thoracic chaetigers (Tc: 18 to 20 ) and the highest number of subpodal papillae (mSpP: 8) in $L$. multipapillatus sp. nov., are significantly higher than in Leitoscoloplos sp. or L. panamensis (both with 17 thoracic chaetigers and up to 4 subpodal papillae on average). Moreover, in L. multipapillatus sp. nov., the number of chaetigers with subpodal papillae (cSpP) is higher (12 on average) than in Leitoscoloplos sp. (10 on average) or L. panamensis (9 on average) (Fig. 1).

Besides the stomach papillae, there were few morphological differences between Leitoscoloplos sp. and $L$. panamensis; the first species was only slightly larger. On the other hand, the specimens of L. panamensis from Panamanian coasts (type material) showed that those specimens are larger (Bln) than those collected in the Gulf of California, and perhaps, the subpodal papillae (fSpP) appear first on posterior neuropodia: chaetigers $15-17$ versus chaetigers $13-15$ in Leitoscoloplos sp. (Fig. 1).

The first four principal components explained nearly $75 \%$ of the total variation of the 14 morphological characters. Of these, the first two explain better most of the data variability (58.58\%) (Table 1). Factor 1 described the highest variance of the model (45.90\%) (Table 1, Fig. 2A-B). The most important variables for factor 1 were the maximum number of stomach papillae $(\mathrm{mStP})$, the number of chaetigers bearing these papillae (cStP), the number of thoracic chaetigers (Tc), and to a lesser degree, the maximum number of subpodal papillae (mSpP) (Table 2, Fig. 2A), which

\begin{tabular}{lcc}
\hline Parameters & Factor 1 & Factor 2 \\
\hline Body length to chaetiger 50 (Bln) & -0.67 & 0.18 \\
Thoracic width at chaetiger 10 (Tw) & -0.66 & 0.56 \\
Number of thoracic chaetigers (Tc) & -0.91 & -0.14 \\
Thoracic length (Tln) & -0.76 & 0.20 \\
First chaetiger with branchiae (fBr) & -0.23 & 0.31 \\
First neuropodium with bifurcate lobes (fBL) & 0.22 & 0.18 \\
Number of chaetigers with interramal cirri (cIC) & -0.11 & 0.85 \\
First chaetiger with interramal cirri (fIC) & -0.60 & -0.39 \\
Maximum number of subpodal papillae (mSpP) & -0.85 & 0.05 \\
Number of chaetigers with subpodal papillae (cSpP) & -0.77 & 0.30 \\
First chaetiger with subpodal papillae (fSpP) & 0.39 & -0.14 \\
Maximum number of stomach papillae (mStP) & -0.91 & -0.27 \\
Number of chaetigers with stomach papillae (cStP) & -0.91 & -0.23 \\
First chaetiger with stomach papillae (fStP) & -0.73 & -0.36 \\
\hline
\end{tabular}

Table 2. Parameters and abbreviations used in the morphometric analysis. Factor 1 and 2 show the respective weights of each parameter in the PCA. The highest weights are indicated in boldface type. For parameter abbreviations see Fig. 1. 
were more correlated to L. multipapillatus sp. nov (Fig. 2B). On the other hand, factor 2, linked to the number of chaetigers with interramal cirri (cIC) and thoracic width (Tw) (Table 2, Fig. 2A), only accounted for $12.68 \%$ of the variability (Table 1 ).
Plotting both components, two main groups emerge (Fig. 2B): one regrouping the specimens with the highest number of thoracic chaetigers (18-20) and numerous stomach papillae $(\mathrm{M})$, and a second one where specimens have fewer than 17 thoracic chaetigers and 0-2

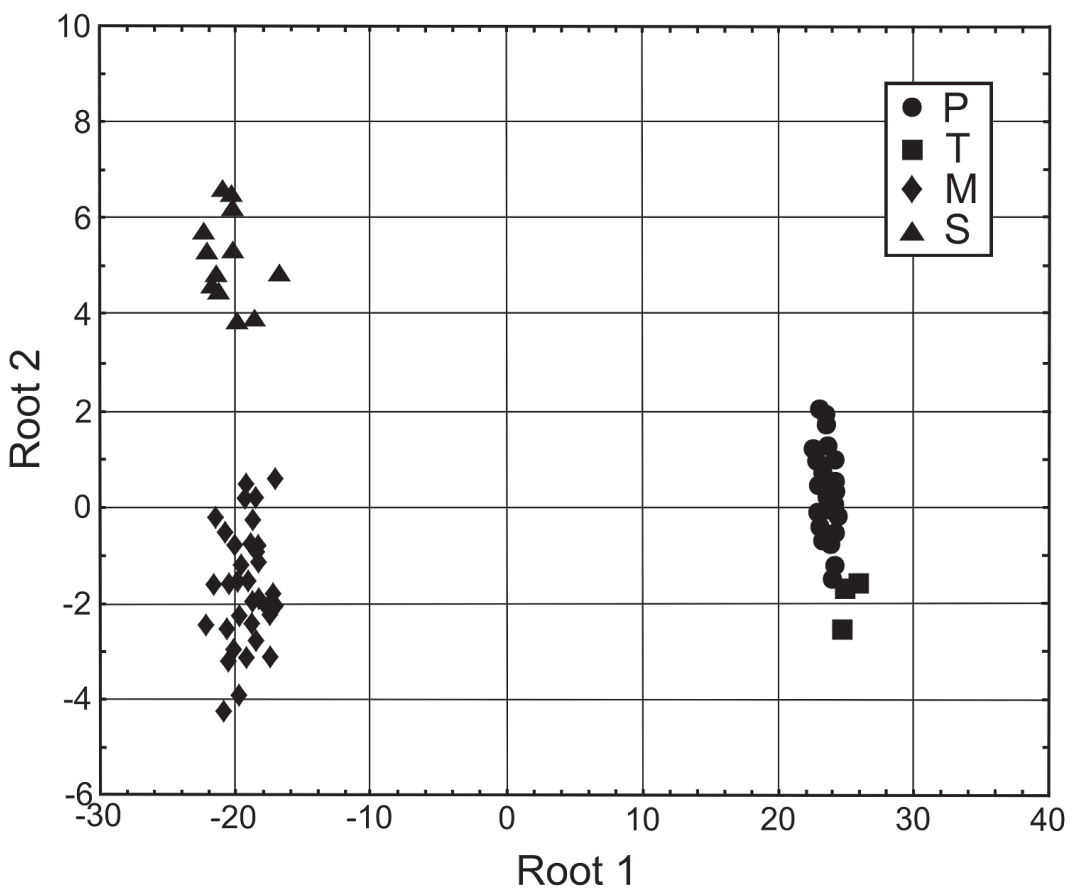

Fig. 3. Canonical analysis based on the first and second discriminant functions: P) Leitoscoloplos panamensis; T) syntypes of L. panamensis; M) Leitoscoloplos multipapillatus sp. nov.; S) Leistoscoloplos sp.

Table 3. Chi-square test with successive roots removed.

\begin{tabular}{lcllccc}
\hline Root & Eigenvalue & Canonical correlation & Wilk's lambda & Chi-square & df & p-level \\
\hline 0 & 488.417 & 0.999 & $0.190 \times 10-3$ & 708.292 & 33 & 0 \\
1 & 5.142 & 0.915 & 0.091 & 197.352 & 20 & 0 \\
2 & 0.781 & 0.662 & 0.562 & 47.597 & 9 & 0 \\
\hline
\end{tabular}

Table 4. Selected variables by discriminant analysis to separate 88 individuals of: Leitoscoloplos panamensis and its type material, Leitoscoloplos multipapillatus sp. nov. and Leitoscoloplos sp.

\begin{tabular}{|c|c|c|c|c|c|}
\hline Variable & Wilks' Lambda & Partial Lambda & F-remove & p-level & Tolerance \\
\hline First chaetiger with stomach papillae (fStP) & 0.028 & 0.007 & 3787.016 & 0.000 & 0.668 \\
\hline Maximum number of stomach papillae (mStP) & $0.208 \times 10^{-3}$ & 0.898 & 2.906 & 0.040 & 0.517 \\
\hline First chaetiger with interramal cirri (fIC) & $0.319 \times 10^{-3}$ & 0.586 & 18.100 & 0.000 & 0.707 \\
\hline Number of chaetigers with stomach papillae (cStP) & $0.264 \times 10^{-3}$ & 0.708 & 10.563 & 0.000 & 0.421 \\
\hline Thoracic length (Tln) & $0.251 \times 10^{-3}$ & 0.745 & 8.805 & 0.000 & 0.459 \\
\hline Thoracic width at chaetiger $10(\mathrm{Tw})$ & $0.228 \times 10^{-3}$ & 0.820 & 5.621 & 0.002 & 0.360 \\
\hline Number of thoracic chaetigers (Tc) & $0.215 \times 10^{-3}$ & 0.868 & 3.906 & 0.120 & 0.520 \\
\hline First chaetiger with subpodal papillae (fSpP) & $0.232 \times 10^{-3}$ & 0.805 & 6.231 & 0.001 & 0.750 \\
\hline First neuropodium with bifurcate lobes (fBL) & $0.202 \times 10^{-3}$ & 0.923 & 2.153 & 0.100 & 0.940 \\
\hline Number of chaetigers with subpodal papillae (cSpP) & $0.198 \times 10^{-3}$ & 0.941 & 1.595 & 0.197 & 0.500 \\
\hline Number of chaetigers with interramal cirri (cIC) & $0.197 \times 10^{-3}$ & 0.950 & 1.342 & 0.267 & 0.563 \\
\hline
\end{tabular}


stomach papillae (P, T and S). The PCA clearly divides the specimens of L.multipapillatus sp. nov. from those of the other taxa, but the specimens of Leitoscoloplos sp. are not isolated. They always appear close to $L$. panamensis, although they tend to separate due to the presence of 1-2 stomach papillae (Fig. 2B).

The Discriminant Analysis supported this arrangement of the data (Fig. 3) since with a Wilks' lambda of 0.00019 (Table 3 ) the test was highly significant ( $p<$ 0.001 ); furthermore, the analysis showed that all of the specimens were correctly classified inside the corresponding group. The forward stepwise method removed three variables (F-value $<1$ ) from the discriminant function model: body length to chaetiger $50(\mathrm{Bln})$, first chaetiger with branchiae (fBR) and the maximum number of subpodal papillae (mSpP). Therefore, 11 variables remained to discriminate between the morphological types (Table 4), suggesting that three distinct taxa are present, L. panamensis, L. multipapillatus sp. nov. and Leitoscoloplos sp., with the type material of L. panamensis linked to the specimens collected in the Gulf of California (Fig. 3). The partial Wilks' Lambda evaluated the individual contributions of the selected characters and, with the lowest value, the first chaetiger with stomach papillae (fStP) was clearly the most important parameter weighted in the discrimination function (Table 4). The number of chaetigers with interramal cirri (cIC), with subpodal papillae $(\mathrm{cSpP})$ and the first neuropodium with bifurcate lobes (fBL), were the characters that added the least to the overall discrimination. Most of the variables included in the model showed tolerance values higher than 0.5 , but the characters linked to the specimens size, i.e. the thoracic width at chaetiger 10 (Tw) and the thoracic length (Tln), did not add to a unique contribution of the discriminatory power since they are $64 \%$ and $58 \%$ redundant with the variables already included (Table 4).

Computing the discriminant functions through a canonical analysis to show how the variables discriminated the different morphological groups, we found that all discriminant functions (canonical roots) were statistically significant (Table 3). The standardized coefficients for canonical variables showed that the first discriminant function accounted for $98.8 \%$ of the explained variance, that is, almost $99 \%$ of all discriminatory power can be explained exclusively by this root (Table 5). Particularly, the first discriminant function was weighted most heavily by the first chaetiger with stomach papillae (fStP), the number of chaetigers with stomach papillae (cStP), and to a lesser extent by the first chaetiger with subpodal papillae (fSpP). The second (1\%) and third $(0.2 \%)$ canonical roots were virtually irrelevant to discriminate the morphological groups, which were marked mostly by the number of chaetigers with stomach papillae (cStP), the first chaetiger with interramal cirri (fIC), the thoracic length (Tln), the number of thoracic chaetigers (Tc) and the first chaetiger with subpodal papillae (fSpP) respectively (Table 5).

As a result of this highly significant contribution of the variables related to the stomach papillae, the plot of the two discriminant functions confirmed the separation of the morphological shapes. It appears that the most important and clear discrimination is possible for specimens of L. panamensis and its type material by the first canonical root (Fig. 3). This root was marked by negative coefficients for the variables associated with the stomach papillae (Table 5); thus, the presence of these morphological characters makes it less likely that the specimens bearing these papillae belong to L. panamensis. The second canonical root seems to distin-

\begin{tabular}{lrrr}
\hline Variable & Root 1 & Root 2 & Root 3 \\
\hline First chaetiger with stomach papillae (fStP) & -1.211 & 0.165 & -0.030 \\
Maximum number of stomach papillae (mStP) & 0.242 & -0.314 & 0.357 \\
First chaetiger with interramal cirri (fIC) & 0.356 & -0.682 & -0.420 \\
Number of chaetigers with stomach papillae (cStP) & -0.517 & -0.704 & -0.150 \\
Thoracic length (Tln) & 0.022 & 0.084 & -1.120 \\
Thoracic width at chaetiger 10 (Tw) & -0.241 & 0.616 & 0.529 \\
Number of thoracic chaetigers (Tc) & -0.002 & -0.376 & 0.557 \\
First chaetiger with subpodal papillae (fSpP) & 0.293 & -0.224 & -0.550 \\
First neuropodium with bifurcate lobes (fBL) & -0.065 & 0.139 & 0.376 \\
Number of chaetigers with subpodal papillae (cSpP) & 0.238 & -0.226 & -0.200 \\
Number of chaetigers with interramal cirri (cIC) & 0.193 & 0.201 & -0.197 \\
\hline Eigenvalue & 488.417 & 5.142 & 0.781 \\
Cumulative proportion & 0.988 & 0.998 & 1.000 \\
\hline
\end{tabular}

Table 5. Standardized coefficients for canonical variables. 
guish mostly between L. multipapillatus sp. nov. and Leitoscoloplos sp. (Fig. 3), since Leitoscoloplos sp. clearly has less stomach papillae on only 1-2 chaetigers, although as we would have expected, according to the eigenvalues, that the magnitude of the discrimination would be much smaller (Tables 3, 5).

This morphological discrimination is highly determined by the presence and distribution of the stomach papillae. Therefore, if the variables associated with this character were filtered, the separation between $L$. panamensis and Leitoscoloplos sp. would be very difficult. The multivariate analysis showed that L. multipapillatus sp. nov. can be kept as a distinct species, mainly because of the higher number of thoracic chaetigers (18-20) and subpodal papillae (mean: 6), but the specimens corresponding to L. panamensis and Leitoscoloplos sp. would remain mixed. Yet, this last taxon association is not homogeneous, since the specimens kept as Leitoscoloplos sp. are more similar to the L. panamensis specimens collected in the Gulf of California than to those from Panama. The fact that syntypes are slightly segregated from specimens from the Gulf is a consequence of the fact that they are larger and that their subpodal papillae and interramal cirri start 1-2 chaetigers later than on those from the Gulf.

\section{Discussion}

Although the systematic position of the family Orbiniidae within the Annelida is still under discussion, and the relationships within the Orbiniidae are not yet clear (Hoffman and Hausen, 2007; Bleidorn et al., 2009), the validity and monophyly of the genus Leitoscoloplos seems adequate (Bleidorn et al., 2009). However, the presence of numerous subpodal and stomach papillae in some specimens from the Gulf of California could modify this claim, because these specimens can be distinguished from all other species of the genus only by the higher number and distribution of these papillae.

As previously mentioned, the occurrence of stomach papillae in other genera of the family, as well as their number and distribution, constitute diagnostic characters to identify and differentiate species (Hartman, 1957; Blake, 1996). However, in the genus Leitoscoloplos, this character had been observed only in L. obovatus Mackie, 1987 (1 stomach papilla), and now in the taxa analysed in this study, Leitoscoloplos sp. (1-2 stomach papilla) and L. multipapillatus sp. nov. (up to 14 stomach papillae). Therefore, to fully understand the importance of these papillae to classify species within the genus, we must wait to find other species bearing this character.

With the current information, we cannot discard the possibility that specimens of Leitoscoloplos sp. can be $L$. panamensis forms with some stomach papillae. Unfortunately, detailed comparison between specimens coming from different marine regions is not possible, since the available type material of L. panamensis consists of only three syntypes that are poorly preserved; also, earlier reports of specimens of L. panamensis from other localities, besides Panama and the Gulf of California, could be questionable: for example, in specimens collected from the central Mexican Pacific (Salazar-Vallejo et al., 1990), branchiae start on chaetigers 11-12 so that, according to the revision by Mackie (1987) and our comments in this study, they could not correspond to L. panamensis.

The distribution of the various species of Leitoscoloplos is still poorly known; most of them have been recorded only from their type localities, while others, initially reported as widely distributed, like L. kerguelensis (McIntosh, 1885), have been revised and found to belong to other morphologically similar species (Mackie, 1987). The genus Leitoscoloplos in the Tropical Eastern Pacific is relatively well represented, since seven species (L.bajacaliforniensis De León-González and RodríguezValencia, 1996, L. fragilis (Verrill, 1873), L. kerguelensis (McIntosh, 1885), L. mexicanus Fauchald, 1972, L. panamensis (Monro, 1933), L.pugettensis (Pettibone, 1957) and L. multipapillatus sp. nov. have been recorded (29\% of all described species). However, in order to assess the phylogeny of the genus Leitoscoloplos, more studies aimed at assessing their important anatomical features and at analysing their intraspecific morphological variability in different geographical regions are necessary.

The morphometric analysis carried out here complements the anatomical observations and contributes to a more detailed taxonomic evaluation. Despite the lack of information on the origin and function of the subpodal and stomach papillae in orbiniids, and on their variations related to their geographic distribution, the designation of this new species of Leitoscoloplos based on classical taxonomy was significantly supported by morphometric tests. This shows that the morphometric approach can be a valuable tool to differentiate cryptic taxa and to choose which anatomical features are more important in identifying species.

\section{Acknowledgements}

Our special thanks go to Gordon Paterson, researcher at the Natural History Museum, London (BMNH) for the loan of the 
type material of Leitoscoloplos panamensis. Thanks are also due to Diana L. Salcedo Oropeza for her help in measuring the specimens and to María Eugenia Zamudio Reséndiz for her assistance with the preparation of figures. We thank Yolanda Hornelas Orozco for her assistance in the processing of the electronic microscopy photographs. Finally, special thanks are also due to Danny Eibye-Jacobsen and the other anonymous reviewer for their very useful remarks which greatly improved the manuscript.

\section{References}

Blake JA. 1996. Family Orbiniidae Hartman, 1942. Pp. 1-26 in: Blake JA, Hilbig B, Scott PH, eds, Taxonomic Atlas of the Benthic Fauna of the Santa Maria Basin and Western Santa Barbara Channel, Vol. 6: The Annelida, Part 3: Polychaeta: Orbiniidae to Cossuridae. Santa Barbara, California: Santa Barbara Museum of Natural History.

Blake JA. 2000. A new genus and species of polychaete worm (Family Orbiniidae) from methane seeps in the Gulf of Mexico, with a review of the systematics and phylogenetic interrelationships of the genera of Orbiniidae. Cahiers de Biologie Marine 41: 435-449.

Bleidorn C. 2005. Phylogenetic relationships and evolution of Orbiniidae (Annelida, Polychaeta) based on molecular data. Zoological Journal of the Linnean Society 144: 59-73.

Bleidorn C, Hill N, Erséus C, Tiedemann R. 2009. On the role of character loss in orbiniid phylogeny (Annelida): Molecules vs. morphology. Molecular Phylogenetics and Evolution 52: 57-69.

Day JH. 1973. New Polychaeta from Beaufort, with a key to all species recorded from North Carolina. NOAA Technical Reports NMFS Circular 375: 1-140.

Day JH. 1977. A review of the Australian and New Zealand Orbiniidae (Annelida: Polychaeta). Pp. 217-243 in: Reish DJ, Fauchald K, eds, Essays on Polychaetous Annelids in Memory of Dr. Olga Hartman. Los Angeles, California: Allan Hancock Foundation.

De León-González JA, Rodríguez-Valencia JA. 1996. Orbiniidae (Polychaeta) from soft bottom of the western coast of Baja California, Mexico. Bulletin of Marine Science 59: 169-174.

Eibye-Jacobsen D. 2002. The Orbiniidae (Annelida: Polychaeta) of the Bioshelf project, Andaman Sea, Thailand. Phuket Marine Biological Center Special Publication 24: 77-99.

Fauchald K. 1972. Benthic polychaetous annelids from deep water off western Mexico and adjacent areas in the eastern Pacific Ocean. Allan Hancock Monographs in Marine Biology 7: 1-575.

Fauchald K. 1977. Polychaetes from intertidal areas in Panama, with a review of previous shallow-water records. Smithsonian Contributions to Zoology 221: 1-81.

Fauchald K, Rouse GW. 1997. Polychaete systematics: Past and present. Zoologica Scripta 26: 71-138.
Hair JF, Anderson RE, Tatham RL, Black WC. 1999. Multivariate Analysis Data. New Jersey: Prentice Hall.

Hartman O. 1942. A review of the types of polychaetous annelids at the Peabody Museum of Natural History, Yale University. Bulletin of the Bingham Oceanographic Collection, Peabody Museum of Natural History, Yale University 8: 1-98.

Hartman O. 1957. Orbiniidae, Apistobranchidae, Paraonidae and Longosomidae. Allan Hancock Pacific Expeditions 15: 211393.

Hernández-Alcántara P, Solís-Weiss V. 1999. Systematics and distribution of the polychaetes (Annelida: Polychaeta) from the sublittoral zone in the Gulf of California. Oceánides 13: 25-38.

Hoffman S, Hausen H. 2007. Chaetal arrangement in Orbiniidae (Annelida, Polychaeta) and its significance for systematics. Zoomorphology 126: 215-227.

Mackie ASY. 1987. A review of species currently assigned to the genus Leitoscoloplos Day, 1977 (Polychaeta: Orbiniidae), with descriptions of species newly referred to Scoloplos Blainville, 1828. Sarsia 72: 1-28.

McIntosh WC. 1885. Report on the Annelida Polychaeta collected by H.M.S. Challenger during the years 1873-1876. Challenger Reports 12: 1-554.

Monro CCA. 1933. The Polychaeta Sedentaria collected by Dr. C. Crossland at Colón, in the Panama region, and the Galapagos Islands during the expedition of the S.Y. St. George. Proceedings of the Zoological Society of London 1933: 10391092.

Pettibone MH. 1957. North American genera of the family Orbiniidae (Annelida: Polychaeta), with descriptions of new species. Journal of the Washington Academy of Sciences 47: 159-167.

Read G, Fauchald K. 2012. Orbiniidae. In: Read G, Fauchald K, eds, World Polychaeta database. Available at http://www. marinespecies.org/aphia.php?p=taxdetails\&id=902. [accessed 25 April 2013]

Rouse GW. 2001. 9. Orbiniidae Hartman, 1942. Pp. 57-60 in: Rouse GW, Pleijel F, eds, Polychaetes. New York: Oxford University Press.

Salazar-Vallejo SI, De León-González JA, Chavez-Comparán C. 1990. Poliquetos (Annelida: Polychaeta) de la Bahía de Manzanillo, Colima, México. Revista de Biología Tropical 38: 211-229.

Verrill AE. 1873. Report upon the invertebrate animals of Vineyard Sound and the adjacent waters, with an account of the physical characters of the region. United States Commission of Fish and Fisheries Report 1871 and 1872: 295-778.

Zar JH. 1996. Biostatistical Analysis. New Jersey: Prentice Hall.

Received: 22 July 2013

Revised and accepted: 3 March 2014

Published online: 2 May 2014

Editor: H.A. ten Hove 


\section{Appendix}

\section{Systematics}

Orbiniidae Hartman, 1942

Leitoscoloplos Day, 1977, emended

Type species: Haploscoloplos bifurcatus Hartman, 1957: 277-279, designated by Day (1977).

Diagnosis. Prostomium pointed, conical, with an achaetous peristomial ring. Thoracic neurochaetae with only crenulated capillaries; abdominal furcate notochaetae present or absent. Branchiae either present from posterior thoracic, transitional or abdominal chaetigers, or absent. Interramal cirri present or absent. Posterior thoracic neuropodia with up to 6 podal papillae. Subpodal and stomach papillae absent, or with up to 8 subpodal papillae per parapodium and with numerous stomach papillae in the posterior thorax/anterior abdomen.

Remarks. In Leitoscoloplos multipapillatus sp. nov., thoracic chaetigers with up to 2 podal papillae are present, which corresponds well to the generic definition (Mackie, 1987; Eibye-Jacobsen, 2002). However, in this new species, a higher number of subpodal papillae (up to 8 per parapodium) are found, and most of all, numerous stomach papillae (up to 14 on each segmental side).

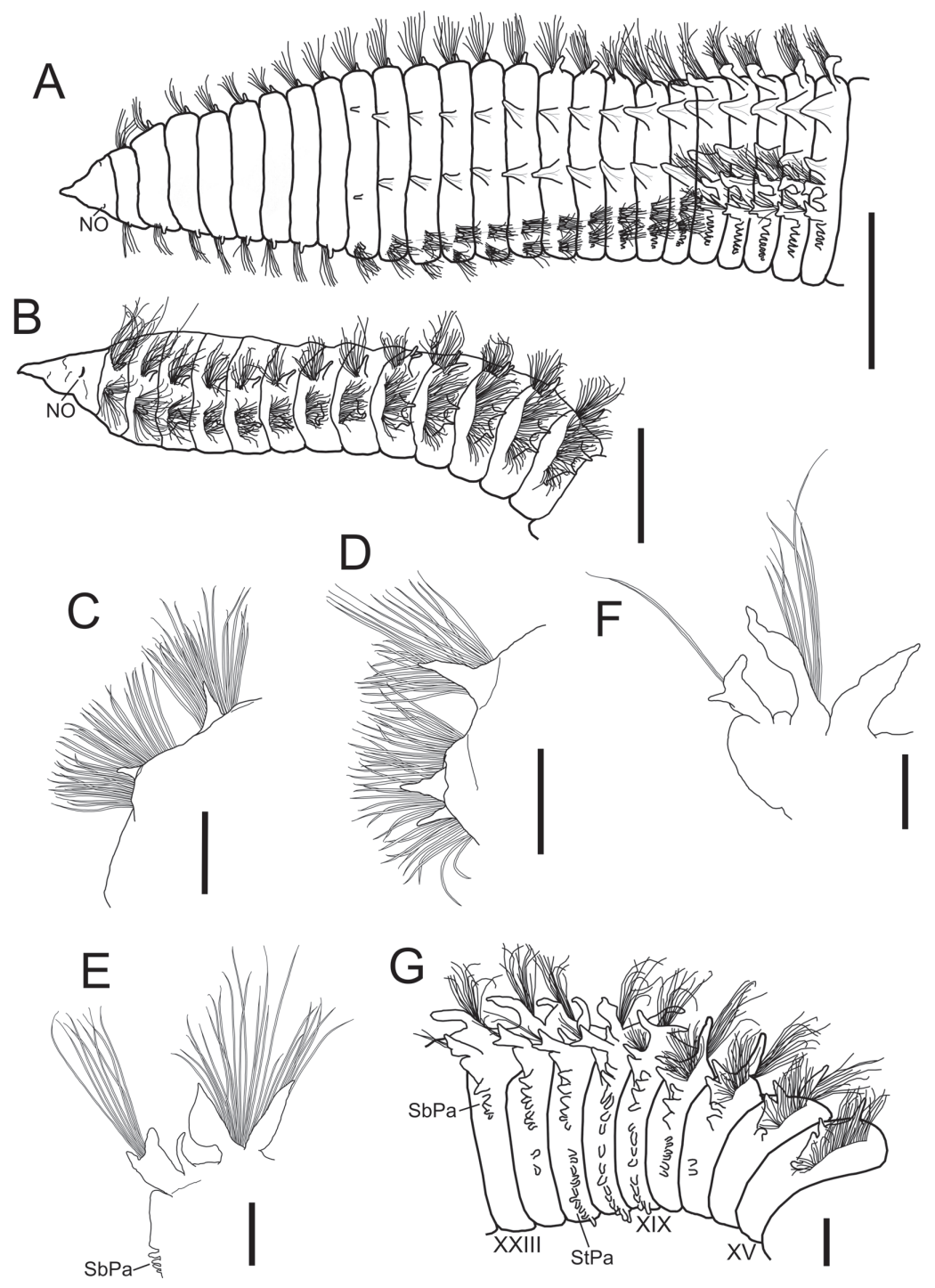

Fig. 4. Leitoscoloplos multipapillatus sp. nov., holotype. A) Anterior end, dorsal view; B) same, lateral view; C) chaetiger 5 , posterior view; D) chaetiger 10 , posterior view; E) chaetiger 24, posterior view; F) chaetiger 30, posterior view; G) chaetigers 15 to 23 , lateral view. (Roman numerals $=$ number of chaetiger; NO =nuchal organs; $\mathrm{SbPa}=$ subpodal papilla; $\mathrm{StPa}=$ stomach papilla). Scale bars: A 1 $\mathrm{mm}$; B $0.5 \mathrm{~mm}$; C-F $0.1 \mathrm{~mm}$; G $0.2 \mathrm{~mm}$. 
Together, they form ventral fringes on some posterior thoracic and anterior abdominal chaetigers. Because of their position, below the neuropodia or on the ventral region of the body, both types of papillae are usually separated by a gap. However, in Leitoscoloplos multipapillatus sp. nov., when these papillae together make continuous ventral fringes on some chaetigers, it is almost impossible to differentiate them. In such cases, it was assumed that there could be up to 8 subpodal papillae by parapodium, because 8 was the maximum number of subpodal papillae observed in the analyzed specimens, when papillae are not clearly placed on the ventral middle region (stomach papillae). So far, no other morphological distinctions between these structures have been observed in orbiniids. (Based on the redefinition of Mackie (1987), the emendations made by Eibye-Jacobsen (2002), and the remarks made in this study.)

Leitoscoloplos multipapillatus sp. nov. (Figs 4A-G, 5A-I, 6A-H)

Leitoscoloplos panamensis.- Hernández-Alcántara and Solís-Weiss 1999: 27 (in part). (not Monro, 1933)

Holotype (CNP-ICML: POH-01-001): Expedition 'Cortés 3': Station 42, Tepoca Cape, Gulf of California $\left(30^{\circ} 12.4^{\prime} \mathrm{N}, 112^{\circ} 47.2^{\prime} \mathrm{W}\right), 23 \mathrm{~m}$, fine sand, collected by P. Hernández-Alcántara, 5 August 1985.

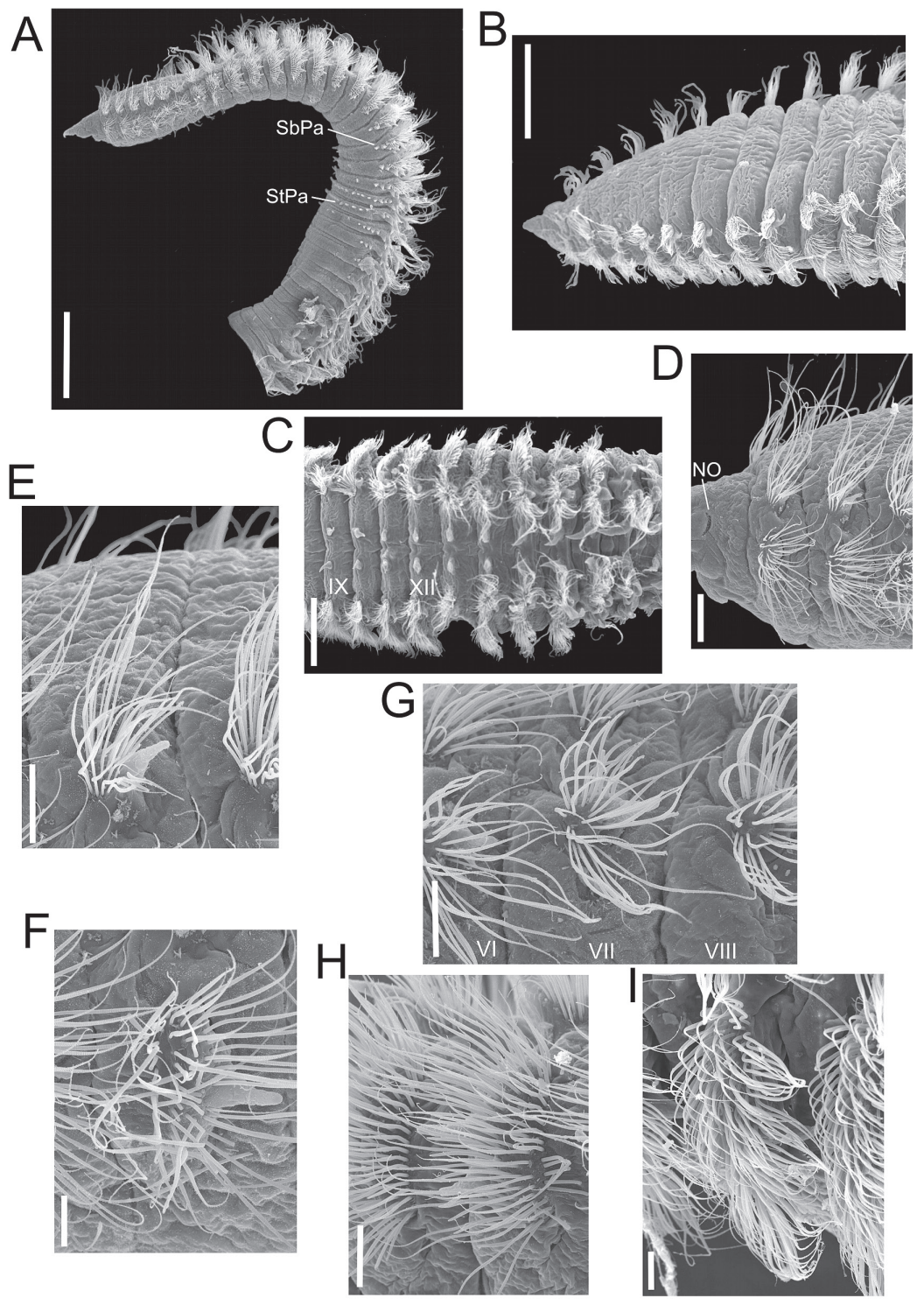

Fig. 5. Leitoscoloplos multipapillatus sp. nov., paratype. A) Thoracic and abdominal region, ventro-lateral view; B) anterior end, dorso-lateral view; C) transition from thorax (left) to abdomen, dorsal view; D) chaetigers 1 and 2, lateral view; E) notopodium from chaetiger 3, anterior view; F) neuropodium from chaetiger 3 , anterior view; G) neuropodium from chaetigers 6-8, anterior view; $\mathrm{H}$ ) neuropodium from chaetiger 11, anterior view; I) neuropodium from chaetiger 8 , frontal view. (Roman numerals=number of chaetiger; $\mathrm{NO}=$ nuchal organ; $\mathrm{SbPa}$ =subpodal papilla; $\mathrm{StPa}=$ stomach papilla). Scale bars: A $1 \mathrm{~mm}$; B, C $0.5 \mathrm{~mm}$; D $0.1 \mathrm{~mm}$; E-I $50 \mu \mathrm{m}$. 
Paratypes (12 specimens): CNP-ICML: POP-01-001: 7 specimens, 2 used for SEM studies, same station as holotype; BMNH: NHMUK ANEA 2014.324-38: 5 specimens, same station as holotype.

Additional material examined. Twenty-five specimens (CNP-ICML: PO-01-028): Expedition 'Cortés 2': 2 specimens, Station 52, El Fuerte River $\left(25^{\circ} 39.9^{\prime} \mathrm{N}\right.$, $\left.109^{\circ} 28.6^{\prime} \mathrm{W}\right), 28 \mathrm{~m}, 20$ March 1985. Expedition 'Cortés 3': 1 specimen, Station 3, Santa María Bay $\left(25^{\circ} 2.4^{\prime} \mathrm{N}, 108^{\circ} 30.5^{\prime} \mathrm{W}\right), 23 \mathrm{~m}$, fine sand, 9 August 1985; 1 specimen, Station 16, Arboleda Point $\left(26^{\circ} 52.7^{\prime} \mathrm{N}, 110^{\circ} 00.8^{\prime} \mathrm{W}\right), 18 \mathrm{~m}$, fine sand, 31 July 1985 ; 1 specimen, Station 27, Northern Tiburón Island $\left(29^{\circ} 28.6^{\prime} \mathrm{N}, 112^{\circ} 26.4^{\prime} \mathrm{W}\right), 34 \mathrm{~m}$, fine sand, 2 August
1985; 5 specimens, Station 32, Willard Point (2946.7’N, $\left.114^{\circ} 20.0^{\prime} \mathrm{W}\right), 21 \mathrm{~m}$, fine sand, 3 August 1985; 7 specimens, Station 42 , Tepoca Cape $\left(30^{\circ} 12.4^{\prime} \mathrm{N}, 112^{\circ} 47.2^{\prime} \mathrm{W}\right)$, $23 \mathrm{~m}$, fine sand, 5 August 1985; 2 specimens, Station 48 , Tastiota $\left(28^{\circ} 15.7^{\prime} \mathrm{N}, 111^{\circ} 35.6^{\prime} \mathrm{W}\right), 54 \mathrm{~m}$, fine sand, 6 August 1985; 2 specimens, Station 52, El Fuerte

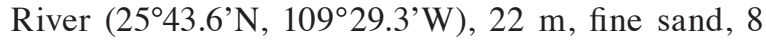
August 1985. Expedition 'Estudio Integral de la Bahía de Mazatlán’: 1 specimen, Station C1, VV8, Mazatlán Bay $\left(23^{\circ} 13^{\prime} \mathrm{N}, 106^{\circ} 27^{\prime} \mathrm{W}\right), 9 \mathrm{~m}, 26$ June 1979; 1 specimen, Station C8, VV6, Mazatlán Bay $\left(23^{\circ} 13^{\prime} \mathrm{N}\right.$, $\left.106^{\circ} 27^{\prime} \mathrm{W}\right), 10 \mathrm{~m}, 25$ January 1980; 1 specimen, Station C10, VV3, Mazatlán Bay $\left(23^{\circ} 13^{\prime} \mathrm{N}, 106^{\circ} 27^{\prime} \mathrm{W}\right), 10 \mathrm{~m}$, 11 April 1980; 1 specimen, Station C10, VV5, Mazat-
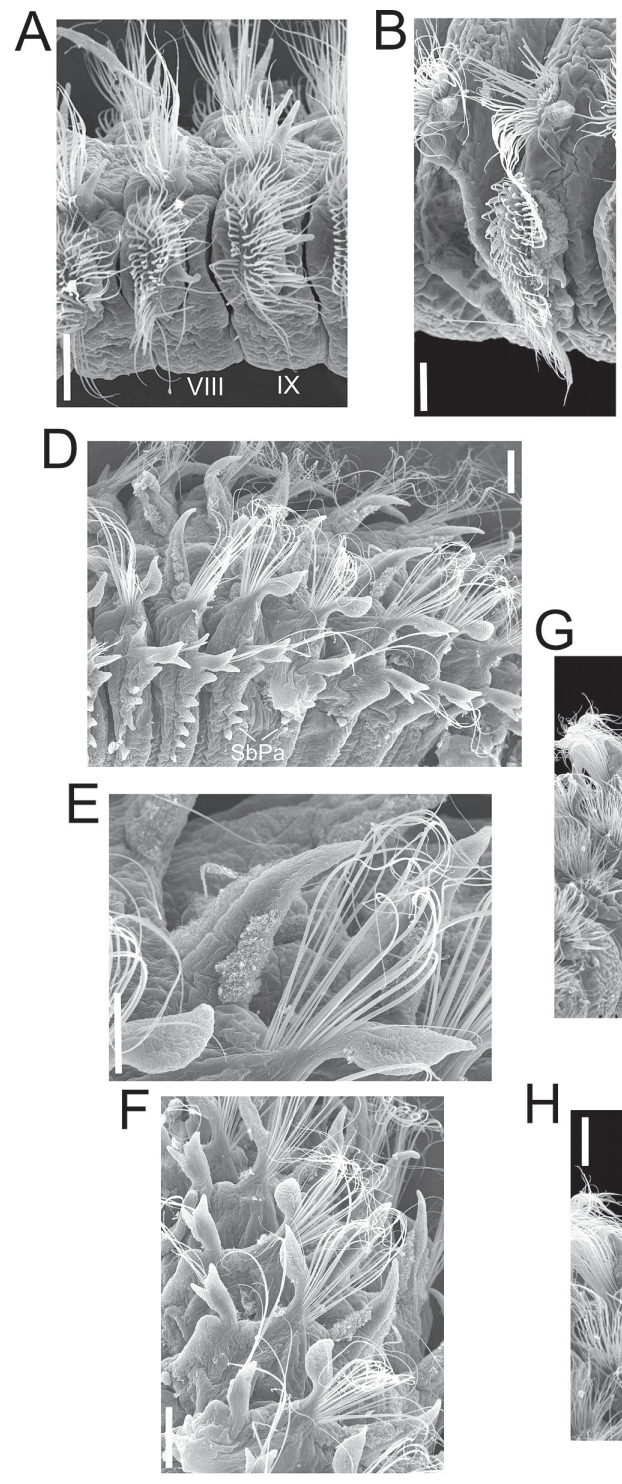
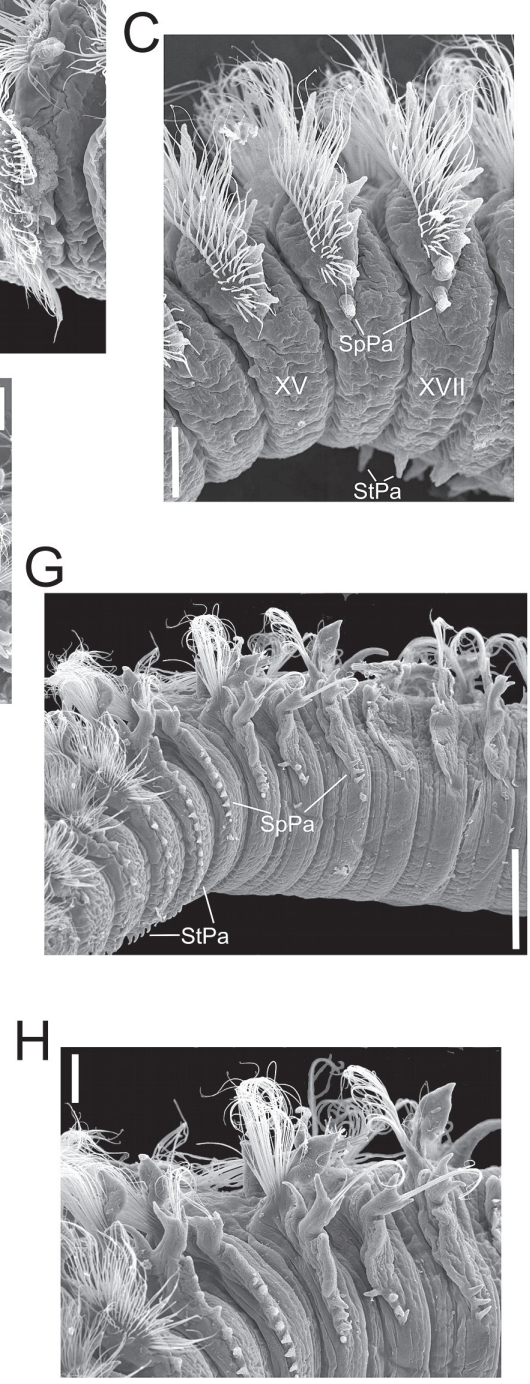

Fig. 6. Leitoscoloplos multipapillatus sp. nov., paratype. A) Chaetigers 8 and 9, anterior view; B) chaetiger 12 , frontal view; C) chaetigers 15 to 17 , anterior view; D) abdominal region, anterior view; E) notopodium from chaetiger 32, anterior view; F) posterior abdominal region, antero-dorsal view; G) transition from thorax (left) to abdomen, ventro-lateral view; $\mathrm{H}$ ) anterior abdominal region, antero-lateral view. (Roman numerals $=$ number of chaetiger; $\mathrm{SpPa}=$ subpodal papilla; $\mathrm{StPa}=$ stomach papilla). Scale bars: A-D, G $0.1 \mathrm{~mm}$; E $50 \mu \mathrm{m} ;$ F $0.2 \mathrm{~mm}$; H $0.5 \mathrm{~mm}$. 
lán Bay $\left(23^{\circ} 13^{\prime} \mathrm{N}, 106^{\circ} 27^{\prime} \mathrm{W}\right), 16 \mathrm{~m}$ depth, 11 April 1980. All localities are in the Gulf of California. All specimens from expeditions 'Cortés 2' and 'Cortés 3' were collected by P. Hernández-Alcántara, all those from Expedition 'Estudio Integral de la Bahía de Mazatlán' were collected by M. Hendrickx.

Description. Holotype and paratypes incomplete. Holotype with 52 chaetigers, $20 \mathrm{~mm}$ long and $2 \mathrm{~mm}$ wide. Paratypes with 33 to 73 chaetigers, 13 to $18 \mathrm{~mm}$ long and 1.5 to $2 \mathrm{~mm}$ wide. Body yellowish in alcohol, divided into a dorso-ventrally flattened thoracic region which consists of the peristomium and 19 chaetigers (18-20 in paratypes), the last one transitional, and a cylindrical abdominal region (Figs 4A-B, 5A). Prostomium conical, sharp, no eyes (Fig. 4A-B). Peristomium achaetous, with a pair of conspicuous lateral nuchal organs in anterior position (Figs 4B, 5D). Branchiae erect, from chaetiger 9 (Figs 4A, 5B), triangular, initially very small but gradually increasing in size along thorax, better developed on abdominal region (Fig. 5C), slightly longer than notopodial postchaetal lamellae, conspicuously fimbriated on both sides (Fig. 6D-F). Parapodia of first chaetiger slightly shifted dorsally (Fig. $5 \mathrm{~B}, \mathrm{D})$. Thoracic notopodia with a small triangular postchaetal lobe from first chaetiger, increasing in length and thickness towards the posterior thorax (Figs $4 \mathrm{~A}-\mathrm{D}, 5 \mathrm{~B}, \mathrm{E})$. Notopodia with numerous very long camerated capillaries arranged in 3-4 rows (Fig. 5E). Thoracic neuropodia of first chaetiger as low transverse ridges, with a rounded postchaetal lamella bearing a podal papilla from chaetiger 1 to 8 (8-9 in paratypes) (Figs 4C, 5F, G); on the first neuropodia, these papillae are very small, difficult to observe (Fig. 5D). From chaetiger 9 (9-10 in paratypes) to the end of the thorax, neuropodia similar in shape but with 2 podal papillae (Figs 4D, 5H, 6A-C). Thoracic neuropodia with numerous camerated capillaries, more or less arranged in 4-6 rows (Figs 5I, 6B); capillaries located on anterior rows shorter than those on posterior rows (Figs 5F,H). Abdomen incomplete, cylindrical in section, notopodia with numerous crenulated capillaries and a broad and foliaceous postchaetal lamella (Figs 5C, 6D-H). No forked or other modified chaetae. Neuropodia bilobed, inner lobe longer, with clear notch at insertion of a well-developed lateral flange (Figs 4E-F, 6H), and supported by a pair of fine aciculae, slightly protruding from distal margin in some posterior chaetigers; they carry 5-15 crenulated capillaries (Figs 4E-F, 6D-H). Interramal cirri present from chaetiger 18 (17-19 in paratypes) (Figs 4E, 6H), progressively becoming indistinct and disappearing (Figs 4F, 6D, F) at chaetiger 25 (24-28 in paratypes). One subpodal papilla (Figs 5A, 6C) from chaetiger 13 (13-15 in paratypes); increasing to 7 papillae (up to 7-8 in paratypes) on chaetigers 20-22 (Figs $4 \mathrm{G}, 6 \mathrm{D}, \mathrm{G}-\mathrm{H})$. With triangular stomach papillae on 6 chaetigers (4-7 in paratypes): from chaetiger 17 (16-18 in paratypes) to chaetiger 22 (20 to 23 in paratypes) (Figs 4G, 5A, 6G). Initially, 2 stomach papillae on each segmental side (1-3 in paratypes), but on 2 or 3 posterior chaetigers (19 to 21 ) the number of stomach papillae can increase to 9-12 (up to a total of 14 in some paratypes), even forming ventral fringes (Figs 4G, 5A, 6G). Pygidium unknown.

Remarks. Based on the system proposed by Mackie (1987) to organize this genus, Leitoscoloplos multipapillatus sp. nov. can be included into species group 5: branchiae present, more than 10 thoracic chaetigers, and bearing interramal cirri and subpodal papillae. This group also includes by L. fragilis (Verrill, 1873), L. robustus (Verrill, 1873), L. obovatus Mackie, 1987, L. mackiei Eibye-Jacobsen, 2002, L. papillatus EibyeJacobsen, 2002 and L. panamensis (Monro, 1933). The last two had been the only species with 4 or more subpodal papillae: L. papillatus has up to 7 subpodal papillae, but only 14-15 thoracic chaetigers and branchiae start from chaetiger 11, while L. panamensis has a maximum of 4 subpodal papillae (5 according to the observations made in specimens of the Gulf of California). Therefore, this new species is just the second one within the genus with numerous subpodal papillae (up to 7-8), but most of all, it is the only species bearing many stomach papillae (up to 14 on each segmental side). Apart from the presence of these stomach papillae, the new species is morphologically similar to L. panamensis, also widely distributed in the study area. The morphometric analyses further validate the establishment of the new species, since most of the parameters evaluated showed significant differences between $L$. multipapillatus sp. nov. and L. panamensis (Fig. 2). Abundant subpodal papillae (up to 6), are present in Leitoscoloplos sp. but stomach papillae are much fewer (1-2) and restricted to only 1-2 posterior thoracic or anterior abdominal chaetigers (Fig. 2).

Previously, stomach papillae were associated with other orbiniid genera, such as Orbinia, Phylo or Scoloplos. In fact, Blake (2000) suggested that all species with stomach papillae and lacking modified spines on thoracic notopodia be assigned to Orbinia, and that the generic assignations of all species referred to Scoloplos should be reassessed on this basis. However, Orbinia, Phylo and Scoloplos all possess modified chaetae (hooks or spines) in the thoracic neuropodia. Conversely, in the 
specimens collected in the Gulf of California, only capillary chaetae are found in all neuropodia, irrespective of size. The lack of modified chaetae was investigated thoroughly and corroborated with SEM pictures of some specimens, confirming their inclusion in Leitoscoloplos.

Habitat. In 9 to $54 \mathrm{~m}$, on fine sand and muddy sand; temperature: 16.8 to $30.3^{\circ} \mathrm{C}$; salinity: 34.2 to $36 \mathrm{psu} ; 3$ to $5.4 \mathrm{ml} / \mathrm{L}$ dissolved oxygen, and 1.9 to $5.3 \%$ organic carbon.

Type locality. Tepoca Cape, northeastern Gulf of California.

Geographical distribution. Widely distributed on the eastern coasts of the Gulf of California.
Etymology. The specific name refers to the presence of numerous stomach papillae, which clearly separates the species from other members of the genus.

Leitoscoloplos panamensis (Monro, 1933) (Figs 7A-I, 8A-F)

Haploscoloplos panamensis Monro, 1933: 1045-1046, fig. la-d; Fauchald, 1977:46; not Hartman, 1957: 277, pl. 28, figs 1-3 (= Scoloplos armiger alaskensis fide Mackie, 1987).

Leitoscoloplos panamensis.- Mackie 1987: 19-20, fig. 20a-e; Hernández-Alcántara and Solís-Weiss, 1999: 27 (in part).

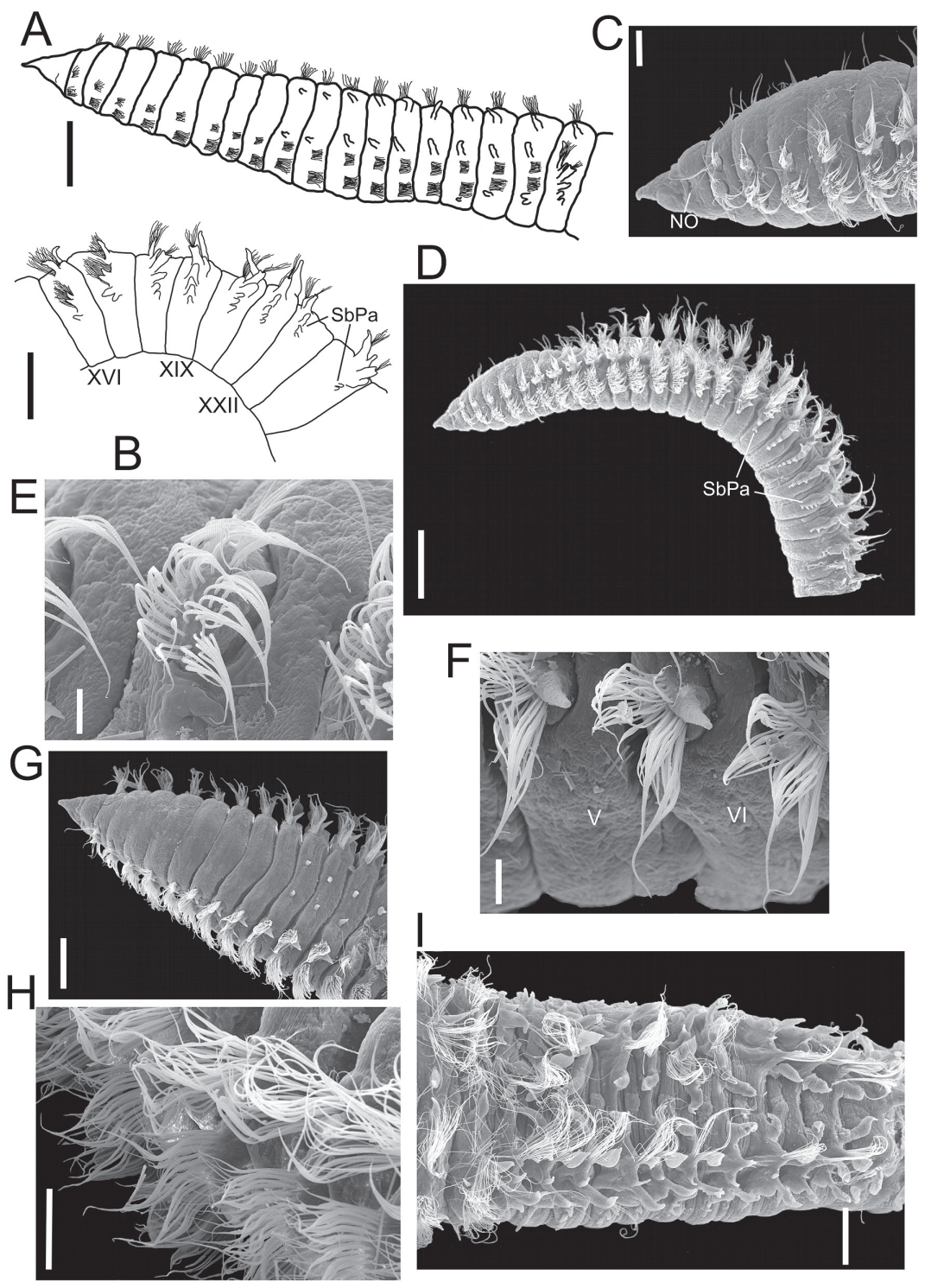

Fig. 7. Leitoscoloplos panamensis (Monro, 1933). A) Thoracic region, dorso-lateral view, syntype; B) chaetigers 16 to 23 , lateral view, syntype; C) anterior end, lateral view; D) anterior and mid-body region, lateral view; E) notopodium from chaetiger 3, frontal view; F) neuropodia from chaetigers 5 and 6 , frontal view; G) anterior end, dorsal view; $\mathrm{H})$ parapodia from posterior thorax, anterior view; I) transition from thorax (left) to abdomen, dorsal view. (Roman numerals=number of chaetiger; $\mathrm{NO}=$ nuchal organ; $\mathrm{SbPa}=$ subpodal papilla). Scale bars: A, D $0.5 \mathrm{~mm}$; B $1 \mathrm{~mm}$; C, H $0.1 \mathrm{~mm}$; E, F 50 $\mu \mathrm{m} ; \mathrm{G}, \mathrm{I} 0.2 \mathrm{~mm}$. 
Type material examined. Three syntypes deposited in the Natural History Museum, London (BMNH, ZK 1933.7.10.63-64). Collected between Taboga and Taboguilla Islands, Pacific coast of Panama, 11-22 m.

Material examined. Thirty-eight specimens (CNPICML: PO-01-018): Expedition 'Cortés 1': 6 specimens, Station 42, Tepoca Cape $\left(30^{\circ} 12.4^{\prime} \mathrm{N}, 112^{\circ} 47.5^{\prime} \mathrm{W}\right), 30$ $\mathrm{m}$, muddy sand, collected by V. Solís-Weiss, 10 May 1982. Expedition 'Cortés 2': 1 specimen, Station 15, Arboleda Point $\left(26^{\circ} 51.1^{\prime} \mathrm{N}, 110^{\circ} 06.5^{\prime} \mathrm{W}\right), 49.8 \mathrm{~m}, 12$ March 1985; 1 specimen, Station 34, Willard Point $\left(30^{\circ} 11.5^{\prime} \mathrm{N}, 114^{\circ} 31.7^{\prime} \mathrm{W}\right), 33 \mathrm{~m}$, muddy sand, 15 March $1985 ; 7$ specimens, Station 42 , Tepoca Cape $\left(30^{\circ} 12.1^{\prime} \mathrm{N}\right.$, $\left.112^{\circ} 46.9^{\prime} \mathrm{W}\right), 30 \mathrm{~m}$, fine sand, 17 March 1985; 1 specimen, Station 44, Tepoca Cape $\left(30^{\circ} 02.4^{\prime} \mathrm{N}, 112^{\circ} 55.4^{\prime} \mathrm{W}\right)$, 104 m, sand, 17 March 1985; 7 specimens, Station 51, El Fuerte River (2542.1'N, 109³0.6'W), 49 m, muddy sand, 20 March 1985. Expedition 'Cortés 3': 1 specimen, Station 15, Arboleda Point ( $\left.26^{\circ} 53.2^{\prime} \mathrm{N}, 110^{\circ} 05.9^{\prime} \mathrm{W}\right), 39$ $\mathrm{m}$, fine sand, 31 July 1985; 1 specimen, Station 32, Willard Point $\left(29^{\circ} 46.7^{\prime} \mathrm{N}, 114^{\circ} 20.0^{\prime} \mathrm{W}\right), 21 \mathrm{~m}$, fine sand, 3 August 1985; 1 specimen, Station 39, Northern Consag
Rocks ( $\left.31^{\circ} 01.83^{\prime} \mathrm{N}, 114^{\circ} 05.3^{\prime} \mathrm{W}\right), 93 \mathrm{~m}$, fine sand, 4 August 1985; 2 specimens, Station 51, El Fuerte River $\left(25^{\circ} 44.3^{\prime} \mathrm{N}, 109^{\circ} 29.4^{\prime} \mathrm{W}\right), 42 \mathrm{~m}$, fine sand, 8 August 1985; 10 specimens, two used for SEM, Station 52, El Fuerte River ( $\left.25^{\circ} 43.6^{\prime} \mathrm{N}, 109^{\circ} 29.3^{\prime} \mathrm{W}\right), 22 \mathrm{~m}$, fine sand, 8 August 1985. All localities are in the Gulf of California, and all specimens from expeditions 'Cortés 2' and 'Cortés 3' were collected by P. Hernández-Alcántara.

Description. Incomplete specimens with 20 to 93 chaetigers; 3 to $19 \mathrm{~mm}$ long and 0.5 to $2.0 \mathrm{~mm}$ wide (syntypes with 37 to 71 chaetigers; 12 to $24.5 \mathrm{~mm}$ long and 0.75 to $1.5 \mathrm{~mm}$ wide). Body yellowish in alcohol. Prostomium conical, with no eyes (Fig. 7A); peristomium bearing a pair of lateral nuchal organs (Fig. 7C). Thorax consisting of 17 chaetigers, last one transitional (Fig. 7A, D) (3 specimens with 16 chaetigers, $0.75-1 \mathrm{~mm}$ wide, and 1 specimen with 15 chaetigers, 1 mm wide; all collected in the Gulf of California). All thoracic parapodia birramous; notopodia with postchaetal lobes from chaetiger 1, increasing in length throughout (Figs 7A, C, E, 8A), becoming broader in posterior thorax (Figs 7G, I, 8C); bearing numerous
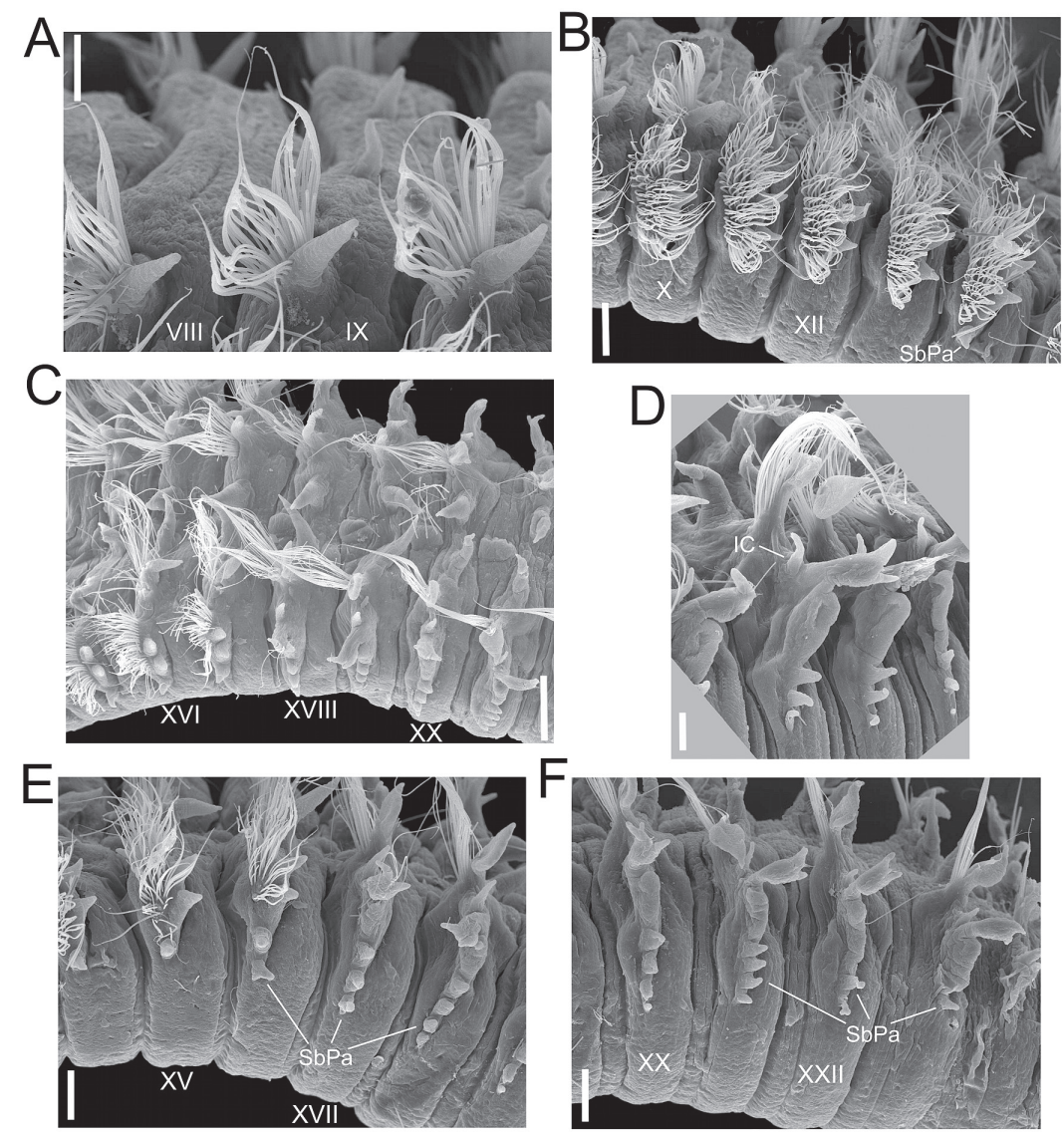

Fig. 8. Leitoscoloplos panamensis (Monro, 1933). A) Notopodia from chaetigers 8 to 10 , dorso-lateral view; B) chaetigers 10 to 14 , lateral view; C) transition from thorax (left) to abdomen, dorso-lateral view; D) chaetiger 20, anterior view; E) chaetigers 15 to 18 , lateral view; F) chaetigers 20 to 23, lateral view. (Roman numerals $=$ number of chaetiger; IC =interramal cirrus; $\mathrm{SbPa}=$ subpodal papilla). Scale bars: A $50 \mu \mathrm{m}$; B, D-F 0.1 $\mathrm{mm}$; C $0.2 \mathrm{~mm}$. 
crenulated capillaries arranged in 2-4 rows (Fig. 7E, $\mathrm{H})$. Neuropodia with 1 podal papilla from chaetiger 2, increasing to 2 papillae from chaetigers 9 or 10 (Figs 7F, 8B-C, E). Abdomen cylindrical in section, notopodial postchaetal lamella broad and foliaceous; neuropodia bilobed, inner lobe longer and more robust (Figs $7 \mathrm{I}, 8 \mathrm{D}, \mathrm{F})$, with a notch at insertion of a lateral flange. Small subpodal papillae from posterior thoracic parapodia (chaetiger 13-15; 15-17 in syntypes), two subpodal papillae on chaetigers 17-18 (16-17 in syntypes), up to 4-5 subpodal papillae on chaetigers 19-23 (3-4 on chaetigers 18-24 in syntypes), decreasing to 1 or 2 in the next 3-4 chaetigers (1-3 chaetigers in syntypes); absent on posterior chaetigers (Figs 7B, D, 8C-F). No stomach papillae. Interramal cirri from chaetigers 15-17 (18 in syntypes), absent after chaetigers 19-29 (24-27 in syntypes) (Figs. 7I, 8C-D). Branchiae from chaetiger 9 (from chaetiger 8 in 1 specimen collected in the Gulf), slender, triangular, initially small, gradually increasing in length towards posterior region (Figs. 7A, G, 8C). All chaetae crenulate capillaries; abdominal neurochaetae weakly crenulate. No forked chaetae.

Remarks. Leitoscoloplos panamensis is included in the group of Leitoscoloplos with more than 10 thoracic chaetigers, bearing interramal cirri and subpodal papillae (Mackie 1987). Revision of available type material deposited in the British Natural History Museum (BMNH) and the specimens collected in the Gulf of California confirmed the occurrence of L.panamensis in this marine region (Hernández-Alcántara and Solís-Weiss 1999), since most of their morphological features agree well with the description (Fig. 2). Besides,

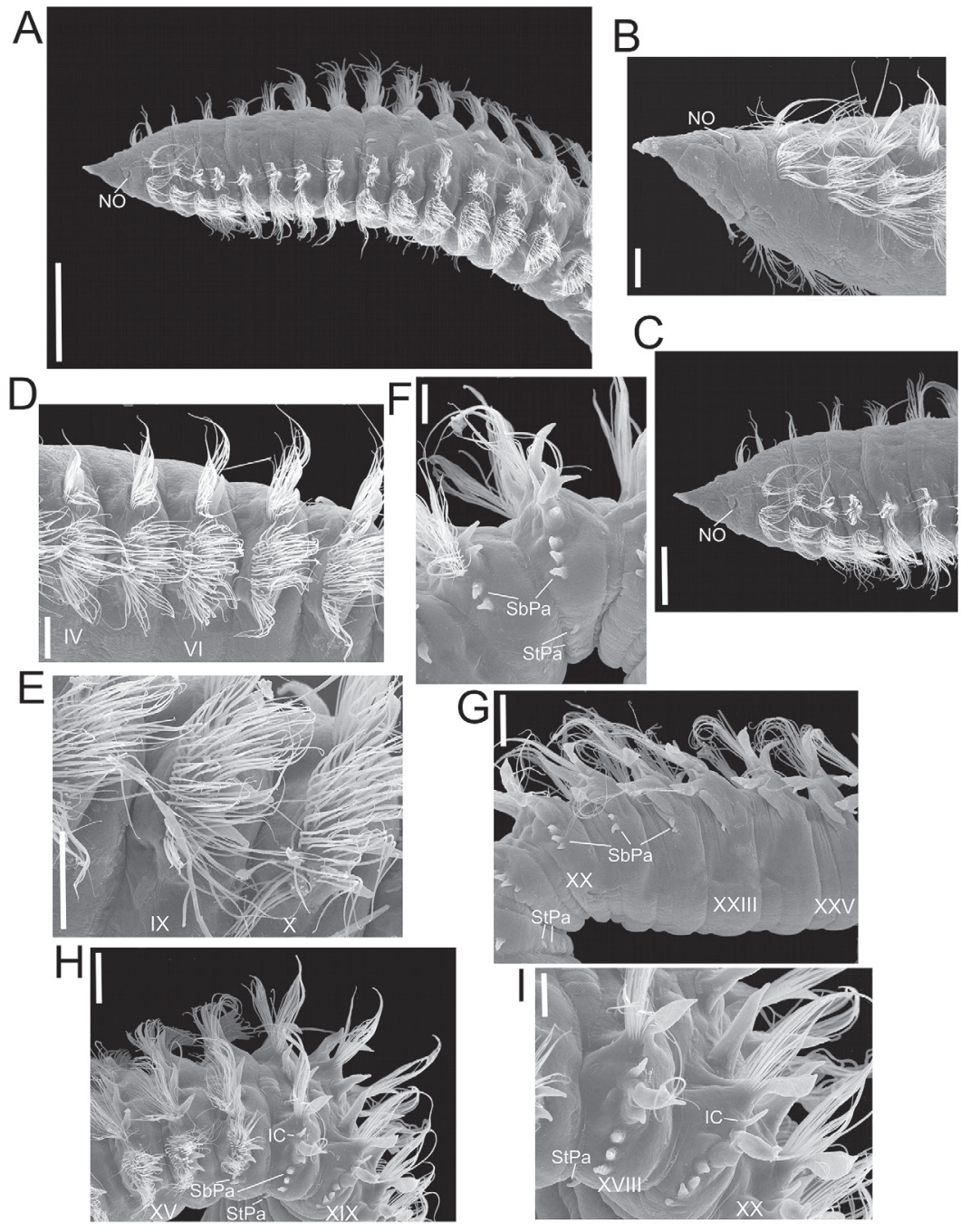

Fig. 9. Leitoscoloplos sp. A) Thoracic region, dorso-lateral view; B) anterior end, ventro-lateral view; C) same, dorsolateral view; D) chaetigers 4 to 8 , anterolateral view; E) neuropodia from chaetigers 9 and 10, anterior view; F) chaetigers 17 and 18, ventro-lateral view; G) anterior abdominal region, ventro-lateral view; $\mathrm{H}$ ) transition from thorax (left) to abdomen lateral view; I) chaetigers 18 to 20 , anterior view. (Roman numerals =number of chaetiger; IC=interramal cirri; $\mathrm{NO}=$ nuchal organ; $\mathrm{SbPa}=$ subpodal papilla; $\mathrm{StPa}=$ stomach papilla). Scale bars: A $0.5 \mathrm{~mm}$; B, D-F, I $0.1 \mathrm{~mm}$; C, G, $\mathrm{H} 0.2 \mathrm{~mm}$. 
we verified that in the type material of L.panamensis, branchiae start at chaetiger 9, as pointed out by Mackie (1987), and not at chaetiger 12 as stated in the original diagnosis (Monro, 1933). In fact, the beginning of branchiae can be considered as a stable feature in this species, since only in one specimen collected in the Gulf did branchiae start at chaetiger 8. Before this study, no other species of the genus had been recorded with more than four subpodal papillae. However, this characteristic is difficult to distinguish in the type material due to the poor condition of the syntypes, as also pointed out by Mackie (1987). In some specimens collected in the Gulf of California, up to five subpodal papillae were observed.

There is not enough material to correlate the morphological variations in size of both groups of L. panamensis (type material from Panama and Gulf of California, this study); however, it is clear that the specimens from Panama are significantly longer than those living in the Gulf of California (Bln: $\mathrm{KW}=6.520, p=0.011$; Tln: $\mathrm{KW}=7.361, p=0.007)$ and that in the type material the interramal cirri $(\mathrm{KW}=12.137, p=0.001)$ and subpodal papillae $(\mathrm{KW}=5.431, p=0.020)$ initially appear 2 to 3 chaetigers later than in the specimens from the Gulf (Fig. 2). Differences found in the other morphological features were small and not significant.

Habitat. In 11 to $22 \mathrm{~m}$ depth (Mackie 1987). In the Gulf of California, this species was collected in 21 to $104 \mathrm{~m}$, on sand, fine sand and muddy sand; temperature 14.1 to $32^{\circ} \mathrm{C}$; salinity 34.2 to $35.9 \mathrm{psu} ; 1$ to $6.5 \mathrm{ml} / \mathrm{L}$ dissolved oxygen and 3.6 to $7.2 \%$ organic carbon.

Geographical distribution. Taboga and Taboguilla Islands, Pacific coast of Panama (Monro, 1933). In northern and central Gulf of California, mainly on its eastern coasts.

\section{Leitoscoloplos sp. (Fig. 9A-I)}

Leitoscoloplos panamensis.- Hernández-Alcántara and Solís-Weiss, 1999: 27 (in part) (not Monro, 1933).

Material examined. Twelve specimens (CNP-ICML: PO-01-029): Expedition 'Cortés 1': 4 specimens, Station 42 , Tepoca Cape $\left(30^{\circ} 12.4^{\prime} \mathrm{N}, 112^{\circ} 47.5^{\prime} \mathrm{W}\right), 30 \mathrm{~m}$, muddy sand, collected by V. Solís-Weiss, 10 May 1982. Expedition 'Cortés 2': 1 specimen, Station 43, Tepoca Cape $\left(30^{\circ} 08.6^{\prime} \mathrm{N}, 112^{\circ} 08.6^{\prime} \mathrm{W}\right), 69 \mathrm{~m}$, muddy sand, 17 March 1985; 1 specimen, Station 51, El Fuerte River $\left(25^{\circ} 42.1^{\prime} \mathrm{N}, 109^{\circ} 30.6^{\prime} \mathrm{W}\right), 49 \mathrm{~m}$, muddy sand, 20 March 1985. Expedition 'Cortés 3': 2 specimens, one used for SEM, Station 42, Tepoca Cape ( $\left.30^{\circ} 12.4^{\prime} \mathrm{N}, 112^{\circ} 47.2^{\prime} \mathrm{W}\right)$,
23 m, fine sand, 05 August 1985; 4 specimens, Station 52, El Fuerte River $\left(25^{\circ} 43.6^{\prime} \mathrm{N}, 109^{\circ} 29.3^{\prime} \mathrm{W}\right), 22 \mathrm{~m}$, fine sand, 8 August 1985. All localities are in the Gulf of California, and all specimens from expeditions 'Cortés 2' and 'Cortés 3' were collected by P. Hernández-Alcántara.

Description. Incomplete specimens with 26 to 102 chaetigers; 5.5 to $32 \mathrm{~mm}$ long and 1 to $2 \mathrm{~mm}$ wide. Body yellowish in alcohol. Prostomium conical, pointed (Fig. 9A-C), with no eyes. Peristomium with a pair of lateral nuchal organs (Fig. 9B-C). Thorax with 16-17 chaetigers, last one transitional (Fig. 9A, F). Branchiae from chaetiger 9 , initially small, gradually increasing in length towards posterior region (Fig. 9A, F, I). All thoracic and abdominal chaetae crenulated capillaries (Fig. 9B, D-E). No forked or modified chaetae. Notopodia with postchaetal lobes from chaetiger 1, increasing in length throughout, becoming broader in posterior thorax, bearing numerous crenulated capillaries (Fig. 9D, H). Neuropodia with 1 podal papilla from first chaetiger (Fig. 9D), 2 papillae from chaetiger 9 or 10 (Fig. 9E-F). Notopodial postchaetal lobe broad and foliaceous in abdomen; neuropodia bilobed, with a notch at insertion of a lateral flange (Fig. 9G-I). Interramal cirri from chaetiger 15-17 (Fig. 9F-I), absent posterior to chaetigers 21-28. Subpodal papillae from posterior thoracic parapodia (chaetiger 13-15), 2 subpodal papillae on chaetigers 15-16 (Fig. 9F), up to 6 subpodal papillae on chaetigers 18-21, decreasing to 1 or 2 in the next 3-4 chaetigers (Fig. 9G-I); absent from chaetigers 22-25. With 1-2 stomach papillae on 1 or 2 posterior thoracic or anterior abdominal segments (between chaetigers 16 and 19), clearly in ventral position (Fig. 9F-I). Pygidium unknown.

Remarks. Leitoscoloplos sp. can be clearly separated from other species of the genus bearing stomach and subpodal papillae, since L. obovatus bears a single small stomach papilla and 1-3 subpodal papillae on 2-3 segments, but has a noticeably lower number of thoracic chaetigers (10-11), and L. multibranchiatus sp. nov. has abundant stomach (up to 14), and up to 8 subpodal papillae. However, it is important to emphasize that, except for the presence of 1-2 stomach papillae on 1-2 chaetigers, Leitoscoloplos sp. is very difficult to separate from L. panamensis. The morphological features in both taxa are almost identical, even if the specimens collected in Panama are longer (Bln: KW= 4.696, $p=0.030$; Tln: $\mathrm{KW}=5.450, p=0.020)$, and their interramal cirri $(\mathrm{KW}=$ $12.137, p=0.001)$ and subpodal papillae $(\mathrm{KW}=5.431$, $p=0.020$ ) first appear on 2-3 chaetigers later than in Leitoscoloplos sp. (Fig. 2). In addition, differences 
between specimens of L. panamensis recorded in the Gulf of California and Leitoscoloplos sp. are even less evident: they can be slightly distinguished because Leitoscoloplos sp. has more subpodal papillae (4 to 6) than L. panamensis from the Gulf (3 to 5). Therefore, and in accordance with the morphometric analyses, we decided not to formally name this material.

The number and distribution of these stomach papillae have been important to identify species in other genera of orbiniids; however, as in other anatomical structures associated with parapodia, their origin and function remain somewhat unknown. For example, the lobe inserted at the base of the neuropodium has sometimes been referred to as ventral cirrus, but it is uncertain that it is homologous to the ventral cirrus of other aciculate polychaetes (Eibye-Jacobsen, 2002).

Habitat. In depths of 22 to $69 \mathrm{~m}$, on fine sand and muddy sand; temperature 14.8 to $30^{\circ} \mathrm{C}$; salinity 34.2 to $35.6 \mathrm{psu} ; 1.8$ to $6.5 \mathrm{ml} / \mathrm{L}$ dissolved oxygen and 4.8 to $8.9 \%$ organic carbon.

Geographical distribution. Eastern coasts of the Gulf of California. 